\title{
Evaluation of Proprotein Convertase Subtilisin/Kexin Type 9: Focus on Potential Clinical and Therapeutic Implications for Low-Density Lipoprotein Cholesterol Lowering
}

\begin{abstract}
Jennifer M. Lose, Michael P. Dorsch, and Barry E. Bleske
Reduction in low-density lipoprotein cholesterol (LDL-C) is associated with a decrease in coronary heart disease (CHD). Statins are currently the most effective medications for LDL-C lowering; however, there continues to be a residual risk for cardiovascular events. Proprotein convertase subtilisin/kexin type 9 (PCSK9) is a protease that promotes LDL receptor degradation, leading to an increase in LDL-C blood levels. Patients with PCSK9 gain-of-function mutations can have up to a 20-fold increase in associated CHD compared with patients without these mutations. Conversely, patients with PCSK9 loss-of-function mutations can have up to an 88\% reduction in CHD without any deficits in neurologic or physiologic functions. PCSK9 can be modulated by current antihyperlipidemic therapies. In particular, statins lead to an increase in PCSK9, which may attenuate their full lipid-lowering effects. These attributes have made PCSK9 inhibition a desirable target for future drug therapies. Current investigational modalities inhibiting PCSK9 will also be discussed.
\end{abstract}

Key Words: PCSK9, cholesterol, low-density lipoprotein, residual risk, hyperlipidemia, statin.

(Pharmacotherapy 2013;33(4):447-460)

The current standard of care for low-density lipoprotein cholesterol (LDL-C) lowering and subsequent decreased risk of coronary heart disease (CHD) is the use of 3-hydroxy-3-methylglutaryl coenzyme A (HMG-CoA) reductase inhibitors (statins). Statin therapy is associated with an approximate 30\% reduction in CHD risk. ${ }^{1}$ Despite the lipid-lowering efficacy of sta-

From the Department of Pharmacy, University of Michigan Hospitals and Health Centers (J.M. Lose and M.P. Dorsch), University of Michigan College of Pharmacy, Ann Arbor, Michigan (B.E. Bleske).

For questions or comments, contact Jennifer Lose, Mayo Clinic, 200 First Street SW, Rochester, MN 55905. e-mail: Lose.Jennifer@mayo.edu. tins, a $70 \%$ residual risk for cardiovascular events remains. Thus, the need for additional LDL-C lowering agents continues to be a high priority. According to the National Health and Nutrition Examination Survey data on lipid management from 2005-2008, 11 million people being treated for hyperlipidemia did not achieve their goal LDL-C based on the National Cholesterol Education Program-Adult Treatment Panel III guidelines. ${ }^{2}$ Many factors contribute to inadequate therapy, including poor or insufficient therapeutic response and adverse effects in response to statins and other lipid-lowering therapies. Continued research into new mechanisms and molecules for LDL-C lowering remains important and necessary. 


\section{Physiology of Proprotein Convertase Subtilisin/ Kexin Type 9}

Proprotein convertase subtilisin/kexin type 9 (PCSK9) is a 692-amino acid protease secreted into the plasma primarily by the liver. PCSK9 binds to hepatic low-density lipoprotein receptors (LDLRs) via the epidermal growth factorlike repeat A (EGF-A) domain and prevents LDLR recycling to the cell surface after endocytosis $^{3}$ (Figure 1). This process results in a reduction in LDLRs on the surface of hepatocytes, decreased cellular uptake of LDL-C, and higher plasma LDL-C levels. ${ }^{6}$ Once in the bloodstream,
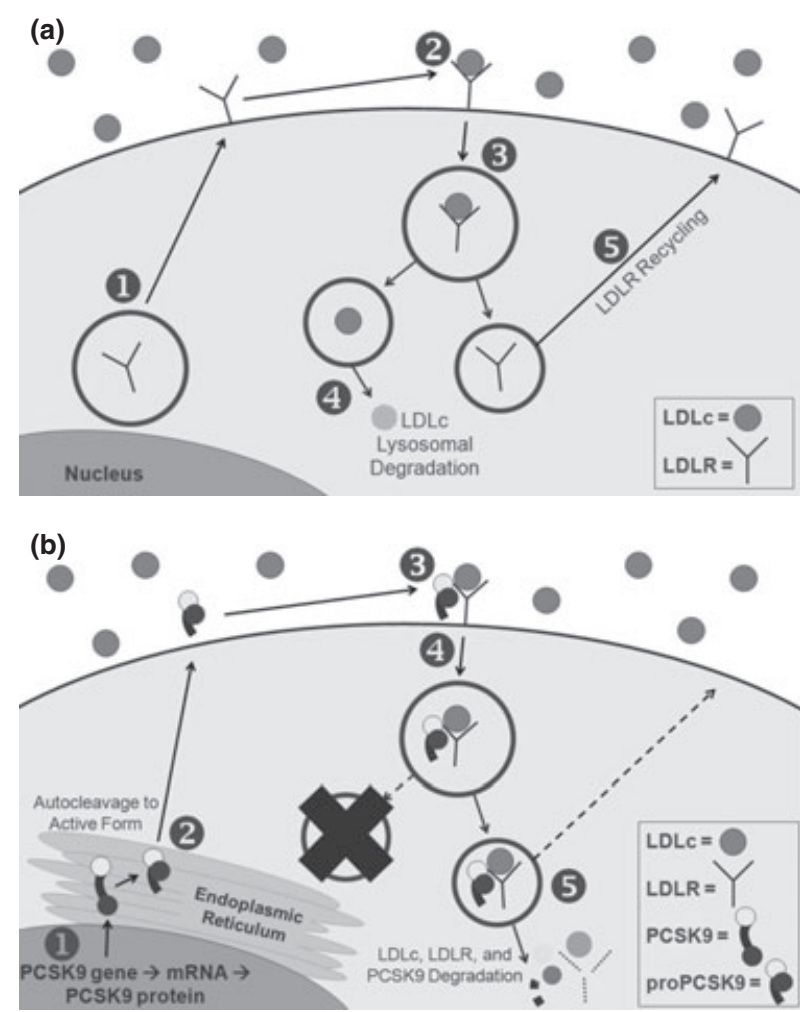

Figure 1. Comparison of a normal low-density lipoprotein receptor (LDLR) life cycle and interaction with proprotein convertase subtilisin/kexin type 9 (PCSK9). (a) As a result of elevated low-density lipoprotein cholesterol (LDL-C [LDLc]) plasma levels, the liver (1) produces LDLRs that (2) bind LDL-C on the hepatocyte cell surface. (3) Endocytosis of the LDLR and bound cholesterol occur. (4) The LDL-C is then lysed, and (5) the LDLR is recycled back to the cell surface to bind more LDL-C. (b) (1) The PCSK9 precursor is produced in the nucleus, then (2) is autocatalytically processed in the endoplasmic reticulum to the active form. (3) In the plasma, active PCSK9 binds to the epidermal growth factor-like repeat A domain of the LDLR and (4) and (5) subsequently targets it for lysosomal destruction within the hepatocyte instead of recycling the LDLR back to the cell surface. In normal physiology, PCSK9 works with LDLR to maintain lipid homeostasis. (Adapted from references 4 and 5.) proPCSK9 is the inactive form of PCSK9 (protein).
PCSK9 can modulate and reduce LDLR expression in the liver, intestines, kidneys, lungs, pancreatic islet cells, and adipose tissues. ${ }^{7-10}$ This enzyme was first discovered in 2003 and was originally named neural apoptosis-regulated convertase 1 (NARC-1), because it was found in the cerebellum and brain telencephalon cells. ${ }^{11}$ Although discovered in the brain, over time researchers have found PCSK9 does not modulate LDLRs in the brain or adrenal glands despite there being a high level of LDLRs in these areas. ${ }^{7}, 10$ The liver is the primary producer and target of PCSK9. The entire role of PCSK9 and its biological purpose in these other tissues have yet to be clearly defined and remain a focus of ongoing research.

PCSK9 transcription is regulated and modulated by several different factors. The most important and predominant transcriptional activator of PCSK9 is sterol response element-binding protein 2 (SREBP-2). ${ }^{12}$ Low intracellular cholesterol activates SREBP-2, leading to PCSK9 expression and LDLR degradation. Other inducers of PCSK9 include activated hepatocyte nuclear factor- $1 \alpha$ (HNF-1 $\alpha$ ), liver X receptor, and insulin. ${ }^{13,14}$ On the other hand, downregulators of PCSK9, which lead to LDLR activation and reduced plasma LDL-C levels, include inflammation, fasting, and lipopolysaccharides such as LDL-C. ${ }^{12}, 13,15-17$ The half-life of PCSK9 is short at approximately 5 minutes and increases to approximately 15 minutes in the absence of LDLRs, suggesting that PCSK9 removal and metabolism are dependent on the hepatically produced LDLRs. ${ }^{7}$

PCSK9 may also play a role in triglyceride metabolism by promoting the degradation of very low-density lipoprotein (VLDL) receptors as evidenced in several murine models. ${ }^{18-21}$ VLDL serves to deliver fatty acids derived from triglyceride-rich lipoproteins to peripheral tissues, including the heart, skeletal muscle, and adipose. ${ }^{22}$ Two studies have shown that PCSK9 levels are correlated with triglyceride levels in humans; however, additional roles of PCSK9 need further study. ${ }^{23,24}$

\section{Role of PCSK9 in the Epidemiology of Heart Disease}

PCSK9 gene mutations were first discovered as a cause of familial hypercholesterolemia in a French family in 2003. ${ }^{25}$ Before this, familial hypercholesterolemia and its subtype, autosomal dominant hypercholesterolemia, had historically been linked to mutations in LDLRs and the LDLR-binding region of apolipoprotein B-100. ${ }^{26}$ 
With the discovery of gain-of-function (GOF) mutations for PCSK9, it is now estimated that $2-3 \%$ of familial hypercholesterolemia cases are secondary to a PCSK9 GOF mutation. At least seven different GOF mutations have been implicated in influencing familial hypercholesterolemia, with the most severe clinical phenotype associated with heterozygous D374Y mutation (rs137852912). ${ }^{27}$ In a cohort of English patients with autosomal dominant hypercholesterolemia, the odds ratio of having CHD was 1.84 for an LDLR mutation (95\% confidence interval [CI], $1.10-3.06, \mathrm{p}=0.05$ ) and 19.96 (95\% CI, 1.88211.55, $\mathrm{p}=0.01$ ) for having the D374Y GOF mutation compared with patients with no detectable mutations after adjusting for age, sex, smoking, and systolic blood pressure. ${ }^{28}$ The D374Y mutation results in a 5- to 30-fold increased affinity for the LDLR than for wildtype PCSK9, making it about 10 times more active in mediating LDLR endosomal degradation. This ultimately leads to higher LDL-C levels and increased CHD risk. ${ }^{26,} 29,30$

Conversely, loss-of-function (LOF) PCSK9 mutations, most commonly R46L (rs11591147), Y142X (rs67608943), or C679X (rs28362286), lead to lower LDL-C levels and a significantly reduced risk of $\mathrm{CHD} .{ }^{31}$ Approximately $2-3 \%$ of all humans are heterozygous for PCSK9 LOF mutations with a correlating $15-40 \%$ reduction in plasma LDL-C and 50-90\% reduction in risk of CHD over 50 years. ${ }^{31,32}$ In one of the largest trials assessing PCSK9 mutations in a cohort of patients, the Atherosclerosis Risk in Communities (ARIC) study, a cohort of black and white subjects were retrospectively reviewed based on the presence or absence of PCSK9 LOF sequence variations. ${ }^{31}$ In the 3363 black subjects, $2.6 \%$ of the subjects had a Y142X mutation $(0.8 \%)$ or a C679X mutation (1.8\%), leading to a $28 \%$ reduction in mean LDL-C and an $88 \%$ reduced risk of CHD ( $p=0.008$ for the reduction; hazard ratio [HR] $0.11 ; 95 \%$ CI $0.02-0.81, \mathrm{p}=0.03$ ). Of the 9524 white subjects examined, 3.2\% of subjects with an R46L mutation had an associated 15\% reduction in LDL-C and a $47 \%$ reduction in the risk of $\mathrm{CHD}$ (HR $0.50 ; 95 \%$ CI $0.32-0.79$; $\mathrm{p}=0.003$ ). These three variants were also studied in subjects aged 4-38 years in the Bogalusa Heart Study. ${ }^{33}$ The purpose was to collect data on the effects of PCSK9 mutations in a younger patient population. As with the white adults in the ARIC study, younger white adult carriers of the R46L mutation had a lower LDL-C level than did noncarriers $\quad(78.9 \pm 21.8$ vs $89.7 \pm 24.9 \mathrm{mg} / \mathrm{dl}$, $\mathrm{p}=0.027$ ) at their first examination (mean age $9.4 \pm 3.2$ yrs). Likewise, black children (mean age $9.0 \pm 3.0$ yrs at their baseline appointment) who were carriers of Y142 or X679 alleles had lower LDL-C levels than did noncarriers $(77.3 \pm 15.1$ vs $91.4 \pm 23.9 \mathrm{mg} / \mathrm{dl}, \mathrm{p}=0.043)$. These results showed that LOF PCSK9 variants are associated with lower LDL-C levels starting early in childhood in patients with wild-type PCSK9 mutations. The LOF-induced, long-term reduction in LDL-C level may result in a greater protective effect against CHD compared with patients with wild-type or GOF PCSK9 mutations.

Another study that may substantiate a greater than expected decrease in CHD based on longterm reduction in LDL-C is a meta-analysis comparing patients with and without the PCSK9 R46L variant. ${ }^{34}$ This study examined the effects of this mutation on LDL-C level, risk of ischemic heart disease (IHD), and mortality. LDL-C level was reduced in carriers versus noncarriers by $12 \%(17 \mathrm{mg} / \mathrm{dl})$. Based on results of a metaanalysis performed by the authors correlating a 39-mg/dl lowering of LDL-C level with reduction in IHD, the anticipated reduction in IHD based on the observed reduction in LDL-C would be 5\% (HR 0.95, 95\% CI 0.93-0.98). However, the actual reduction in IHD risk was greater than expected at 28\% (HR 0.72, 95\% CI $0.62-0.84, \mathrm{p}$ value for difference of predicted vs observed <0.001) in this analysis. This study observed that the PCSK9 LOF genotype may be a better predictor of IHD risk than LDL-C level measurements quantified for an adult.

The PCSK9 R46L variant has also been found to contribute to the interindividual LDL-C lowering response to statin therapy. ${ }^{35}$ In an analysis of the Justification for the Use of Statins in Prevention: An Intervention Trial Evaluating Rosuvastatin (JUPITER) trial data, overall treatment with rosuvastatin $20 \mathrm{mg} /$ day in compliant patients resulted in a median reduction in LDL-C level of $54 \mathrm{mg} / \mathrm{dl}$, with a large interquartile range of $40-66 \mathrm{mg} / \mathrm{dl}$. Four single nucleotide polymorphisms were associated with genomewide reduction in LDL-C level, including PCSK9 $\left(p<5 \times 10^{-8}\right)$. A direct relationship between the number of allele mutations and median absolute reduction in LDL-C level was observed. Patients with more LDL-C lowering alleles in these four single nucleotide polymorphisms had higher median reductions in LDL-C level: $40 \mathrm{mg} / \mathrm{dl}$ for three or fewer 3 alleles up to a $64-\mathrm{mg} / \mathrm{dl}$ reduction for eight alleles $\left(p=6.2 \times 10^{-20}\right.$ for the 
trend). Because a reduction in cholesterol level is associated with a reduction in vascular events, genetic variations such as R46L may account for differences in risk among patients treated with statins. $^{36}$

Most interestingly, as noted in the ARIC trial and in several other studies, patients without PCSK9 appear to be healthy and with normal physiologic function, even with extremely low LDL-C levels. ${ }^{26}, 31,37$ Case reports discuss patients with LDL-C levels of 14 and $15 \mathrm{mg} / \mathrm{dl}$ as a result of LOF mutations who lack any physical, functional, or neurologic alterations. ${ }^{38,} 39$ Similarly, patients with PCSK9-associated hypobetalipoproteinemia, a heterogeneous group of monogenic disorders characterized by very low plasma LDL-C levels, lack functional and neurologic disorders. These findings are in stark contrast to hypobetalipoproteinemia caused by apolipoprotein B or microsomal transfer protein, which can cause malnutrition, steatorrhea, liver steatosis, and neurologic disorders. ${ }^{40,41}$

As other physiologic roles of PCSK9 are discovered outside the primary mechanism of LDLR regulation, research involving the role of PCSK9 in alternative disease states could also be warranted. PCSK9 is being assessed in clinical trials for its relevance as a potential biomarker in acute coronary syndrome (ClinicalTrials.gov identifier NCT01109706). In addition, the effect of PCSK9 on VLDL receptors could affect the treatment of mixed dyslipidemias associated with metabolic syndrome and diabetes mellitus. PCSK9 inhibition may reduce vascular exposure to triglyceride-rich lipoproteins and prevent hepatic steatosis. ${ }^{18,}{ }_{21}$ Furthermore, recent research attempting to elucidate the mechanism linking hepatic insulin signaling to normal, sustained LDLR levels found that insulin receptor knockdown in mice leads to decreased hepatic mammalian target of rapamycin complex 1 signaling, decreased LDLR expression, and increased PCSK9 expression. ${ }^{42}$ Ultimately, this results in increased LDL-C levels. This may provide some insight into the mechanism causing mammalian target of rapamycin inhibitorinduced LDL-C elevations seen in transplant patients.

\section{Influence of Current Antihyperlipidemic Drugs on PCSK9}

The effects of current hypolipidemic agents on PCSK9 levels have been studied extensively. Several studies show that statin treatment promotes a significant increase in plasma PCSK9 levels from baseline to $47 \%$, depending on the dose and potency of the statin (Figure 2) ${ }^{43-48}$ For example, after initiation of atorvastatin $10 \mathrm{mg} /$ day in a small cohort, circulating PCSK9 levels increased by an average of $7.4 \% .{ }^{44}$ In addition, atorvastatin $40 \mathrm{mg} /$ day and rosuvastatin $20 \mathrm{mg} /$ day resulted in increases in PCSK9 levels of 34\% and 28-35\%, respectively. ${ }^{47,}{ }^{49}$ Statin-induced PCSK9 increases generally occur rapidly, and high PCSK9 levels are maintained during statin therapy. In a study of patients given atorvastatin $80 \mathrm{mg} /$ day, a $47 \%$ increase in PCSK9 levels was seen at 4 weeks and was sustained through the remaining 12 weeks of treatment. ${ }^{48}$ The increases in PCSK9 have been inversely correlated with reductions in LDL-C. ${ }^{44}$

The proposed mechanism for PCSK9 elevation is an increase in SREBP-2, a transcription factor, via statins. This leads to both an increase in LDLRs and an increase in PCSK9. Although an increase in LDLRs is desirable for cholesterol lowering, the subsequent increase in PCSK9 level can attenuate LDLR numbers and thus the LDL-C lowering effects of the statin. Initial dosing of statin medications results in a projected decrease of at least $27 \%$ in LDL-C level. However, an increase in the statin dose has a lower than expected further reduction in LDL-C: only 6-7\%. This phenomenon has been termed the "rule of 7." "50 A current hypothesis surrounding this phenomenon is that statin-induced increases in PCSK9 atten-

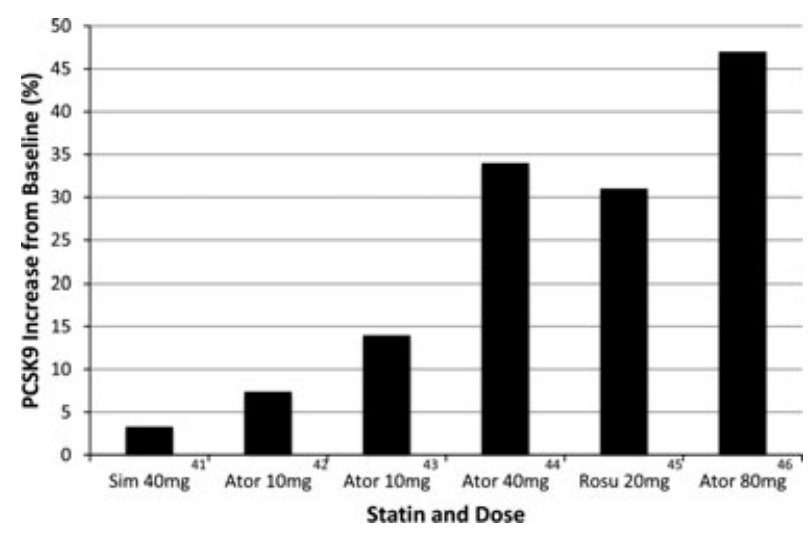

Figure 2. Percent increase in proprotein convertase subtilisin/kexin type 9 (PCSK9) level from baseline after administration of daily doses of statins in clinical trials. Data are shown in ascending order of statin potency for lowdensity lipoprotein cholesterol lowering, starting with the least potent statin (simvastatin $40 \mathrm{mg}$ ) to the most potent statins (equipotent rosuvastatin $20 \mathrm{mg}$ and atorvastatin $80 \mathrm{mg}){ }^{43-48}$ Sim = simvastatin; Ator = atorvastatin; Rosu = rosuvastatin. 
uate the ability of the drugs to reduce LDL-C to their full potential. ${ }^{51,52}$ Drugs that inhibit PCSK9 may provide a synergistic LDL-C lowering benefit when used in combination with a statin.

Fibrates also have been shown to influence PCSK9 plasma levels; however, trial results are conflicting. Fibrates are peroxisome proliferator activated receptor- $\alpha$ agonists that upregulate genes, leading to an increase in high-density lipoprotein cholesterol (HDL-C) production and secretion while also reducing VLDL and triglyceride secretion. This class of drugs is primarily used to treat hypertriglyceridemia and to lower HDL-C. The exact mechanism in relation to changes in PCSK9 is unknown, and clinical studies have shown both an increase and a decrease in PCSK9 levels as result of fibrate use $^{44,53-57}$ (Table 1).

Minimal data are available at this time regarding the effects of ezetimibe monotherapy on PCSK9 levels; however, one study did show that plasma PCSK9 levels are further increased when ezetimibe is combined with statin therapy (Table 2). ${ }^{58}$ The use of ezetimibe as an antihyperlipidemic medication has fallen out of favor due to a lack of evidence for cardiovascular risk reduction. ${ }^{60-62}$ No data have been published assessing any potential impact of bile acid resins, niacin, or any other cholesterol-lowering medication on PCSK9 levels.

\section{Medications in the Pipeline Involving PCSK9 Inhibition}

The large reduction in LDL-C and risk of CHD without any apparent associated adverse effects observed in patients with PCSK9 LOF mutations has made PCSK9 a desirable target for pharmacologic lipid lowering. Likewise, a PCSK9-inhibiting agent may be able to attenuate the increase in PCSK9 levels resulting from the use of current antihyperlipidemic therapies, in particular, statins. The use of concomitant therapies may create a larger, more consistent, and predictable LDL-C lowering response. There are currently four proposed mechanisms for PCSK9 inhibition (Figure 3). The majority of the information and data to date are from animal studies. Human data are still in preclinical, phase I, and phase II trials (Table 3).

One of the most promising and sought-after mechanisms is the use of oligonucleotides, either antisense oligonucleotides or small interfering RNA. Oligonucleotides induce PCSK9 messenger
RNA degradation and disrupt gene translation, resulting in the silencing of the gene. Preclinical human data on the investigational compound ALN-PCSO2 (Alnylam Pharmaceuticals, Inc., Cambridge, MA) shows silencing of PCSK9 messenger RNA in the liver and reduced plasma PCSK9 protein levels of up to $90 \%$ after an intravenous infusion (NCT01437059). A reduction in LDL-C of greater than $50 \%$ was attained rapidly and lasted for several weeks after a single dose. Also, there were no serious adverse events or liver enzyme level elevations. Preclinical trials of SPC-5001 (Santaris Pharma A/S, Horsholm, Denmark), an antisense oligonucleotide, were promising, with decreases in LDL-C level of 74\%; however, phase I trials were terminated for undisclosed reasons (NCT01350960). Phase I trials of a similarly constructed compound, BMS-844421 (Bristol-Myers Squibb, New York, NY, and Isis Pharmaceuticals, Carlsbad, CA), were also terminated for undisclosed reasons (NCT01082562).

A second proposed target is to attack the PCSK9 protein itself and inhibit the self-cleavage of proPCSK9. Because self-cleavage is necessary for binding of PCSK9 to the LDLR, LDLR attenuation will not occur. This is the same mechanism seen with the LOF variant Q152H. ${ }^{63}$ The amino acid substitution occurs in the cleavage site and prevents autocatalytic cleavage of PCSK9. This results in retention of the protein within the endoplasmic reticulum and a $48 \%$ reduction in LDL-C. Although plausible, chemicals tested with these mechanisms have not made it past phase I trials.

The most extensively investigated mechanism to date is the use of a neutralizing monoclonal antibody. These antibodies bind directly to PCSK9 in a region close to that involved in the interaction with the LDLR, thus preventing the binding of PCSK9 to LDLR. Several experimental antibodies structurally mimic the LDLR EGF-A domain or bind directly to the EGF-A domain, preventing PCSK9 binding. ${ }^{64,} 65$

AMG 145 (Amgen Inc., Thousand Oaks, CA) is a subcutaneously injected human monoclonal antibody that binds directly to human PCSK9 to prevent binding to the LDLR. Results from phase I trials showed a reduction in plasma LDL-C by $50-70 \%$ after a single dose. ${ }^{66}$ Duration of effect is dose dependent, and the LDL-C nadir occurred within 2 weeks of dosing in healthy volunteers. The LDL-C level was lowered even further when used in addition to statin therapy in another phase I study. ${ }^{67}$ No discontinuations 
Table 1. Effect of Fibrates on PCSK9 in Clinical Trials

\begin{tabular}{|c|c|c|c|}
\hline Intervention & Treatment Duration (wks) & $\begin{array}{l}\text { Change in Serum } \\
\text { PCSK9 Level (\%) }\end{array}$ & Comments \\
\hline $\begin{array}{l}\text { Fenofibrate } 160 \mathrm{mg} / \text { day } \\
\text { and/or atorvastatin } 10 \mathrm{mg} / \text { day } \\
\text { in patients with diabetes mellitus, } \\
\mathrm{TG}>150 \mathrm{mg} / \mathrm{dl} \text {, and } \\
\mathrm{LDL}-\mathrm{C}>100 \mathrm{mg} / \mathrm{dl} \\
(26 \text { patients randomized; } \\
17 \text { completed study })^{53}\end{array}$ & $\begin{array}{l}12 \text { wks ( } 6 \text { wks with } \\
\text { fenofibrate or atorvastatin } \\
\text { followed by } 6 \text { wks of } \\
\text { atorvastatin }+ \text { fenofibrate) }\end{array}$ & $\begin{array}{l}\text { Day } 1 \text { : atorvastatin: } \\
+24 \%(\mathrm{p}<0.01) \\
\text { fenofibrate: } \\
\text { no significant } \\
\text { change }(\mathrm{p}=\mathrm{NS}) \\
\text { Week } 6 \text { : atorvastatin: } \\
\quad+14 \%(\mathrm{p} \leq 0.01) \\
\text { fenofibrate: }+26 \% \\
\quad(\mathrm{p} \leq 0.01) \\
\text { Atorvastatin }+ \text { fenofibrate: } \\
+42 \% \text { from baseline } \\
\text { at } 3 \text { wks }(\mathrm{p}=\mathrm{NS}) \\
+19 \% \text { at } 6 \text { wks }(\mathrm{p} \leq 0.01)\end{array}$ & \\
\hline $\begin{array}{l}\text { Micronized fenofibrate } \\
67 \mathrm{mg} \text { t.i.d. }(\mathrm{n}=9) \\
\text { and gemfibrozil } 600 \mathrm{mg} \\
\text { b.i.d. }(\mathrm{n}=10) \\
(12 \text { men, } 7 \text { women })^{44}\end{array}$ & 24 wks & $\begin{array}{l}\text { Fenofibrate }+ \text { gemfibrozil: } \\
\quad+17.01 \%(\mathrm{p}=0.031) \\
\text { Atorvastatin: } \\
\quad+7.40 \%(\mathrm{p}=0.033)\end{array}$ & $\begin{array}{l}\text { Inverse correlation } \\
\text { between percent } \\
\text { changes in the levels } \\
\text { of PCSK9 and LDL-C } \\
(\mathrm{r}=-0.558, \mathrm{p}=0.013), \\
\text { attributable to significant } \\
\text { association between these } \\
\text { two parameters in the } \\
\text { men }(\mathrm{r}=-0.622 \text {, } \\
\mathrm{p}=0.031) \text { but not in the } \\
\text { women }(\mathrm{r}=-0.464, \\
\mathrm{p}=0.302)\end{array}$ \\
\hline $\begin{array}{l}\text { Fenofibrate } 200 \mathrm{mg} / \text { day vs } \\
\text { placebo in patients } \\
\text { with low HDL-C } \\
(<45 \mathrm{mg} / \mathrm{dl} \text { for men } \\
\text { or }<50 \mathrm{mg} / \mathrm{dl} \text { for women }) \\
\text { TG } 150-600 \mathrm{mg} / \mathrm{dl} \text {, } \\
\text { and LDL-C }<160 \mathrm{mg} / \mathrm{dl} \\
(\mathrm{n}=39)^{54}\end{array}$ & 12 wks & $\begin{array}{l}\text { Fenofibrate: }+25 \% \text { from } \\
\text { baseline }(\mathrm{p}=0.01) \\
\text { Placebo: no change } \\
\text { from baseline }\end{array}$ & $\begin{array}{l}\text { Fenofibrate-induced } \\
\text { increases in serum } \\
\text { PCSK9 levels were } \\
\text { highly correlated with } \\
\text { fenofibrate-induced } \\
\text { changes in HDL-C, TG, } \\
\text { and LDL-C levels }\end{array}$ \\
\hline $\begin{array}{l}\text { Bezafibrate } 400 \mathrm{mg} / \text { day or } \\
\text { fenofibrate } 200 \mathrm{mg} / \text { day } \\
\text { in patients with impaired } \\
\text { glucose tolerance or } \\
\text { T2DM (open, randomized, } \\
\text { 4-phase crossover study [n=14]) }\end{array}$ & $\begin{array}{l}20 \text { wks (one fibrate } \\
\text { for } 8 \text { wks, then } \\
\text { discontinued for } \\
4 \text { wks, then } \\
\text { switched to other } \\
\text { fibrate for } 8 \text { wks) }\end{array}$ & $\begin{array}{l}\text { Bezafibrate: }+39.7 \% \\
\quad(p<0.001) \\
\text { fenofibrate: }+66.8 \% \\
\quad(p<0.001)\end{array}$ & $\begin{array}{l}\text { Both bezafibrate and } \\
\text { fenofibrate decreased } \\
\text { TG from baseline: } \\
-38.3 \% \text { with } \\
\text { bezafibrate }(\mathrm{p}<0.001) \\
\text { and }-32.9 \% \text { with } \\
\text { fenofibrate }(\mathrm{p}<0.01) \\
\text { and increased HDL-C } \\
\text { from baseline: }+18.0 \% \\
\text { with bezafibrate } \\
\text { ( }<<0.001) \text { and }+11.7 \% \\
\text { with fenofibrate }(\mathrm{p}<0.001)\end{array}$ \\
\hline $\begin{array}{l}\text { Fenofibrate } 200 \mathrm{mg} / \text { day in } \\
\text { patients with diabetes } \\
\text { mellitus (FIELD study }[\mathrm{n}=115])^{56}\end{array}$ & 6 wks & $\begin{array}{l}\text { Fenofibrate: }-8.5 \% \\
(\mathrm{p}=0.041 \text { vs } \\
\text { pretreatment })\end{array}$ & $\begin{array}{l}\text { PCSK9 concentrations } \\
\text { correlated with TC } \\
(\mathrm{r}=0.45, \mathrm{p}=0.006) \\
\text { and LDL-C }(\mathrm{r}=0.54 \\
\mathrm{p}=0.001) \text { but not } \\
\text { with TG or HDL-C }\end{array}$ \\
\hline $\begin{array}{l}\text { Fenofibrate } 145 \mathrm{mg} / \text { day vs } \\
\text { placebo in statin-treated } \\
\text { T2DM patients (double-blind, } \\
\text { crossover study } \\
\text { [13 men, } 2 \text { women] })^{57}\end{array}$ & 12 wks & $\begin{array}{c}\text { Fenofibrate: }-13 \% \text { vs } \\
\text { placebo }(p<0.05)\end{array}$ & \\
\hline
\end{tabular}

Proprotein convertase subtilisin/kexin type 9 = PCSK9; NS = not statistically significant; TG = triglycerides; LDL-C = low density lipoprotein cholesterol; HDL-C = high-density lipoprotein cholesterol; T2DM = type 2 diabetes mellitus; FIELD = Fenofribrate Intervention and Event Lowering in Diabetes; TC $=$ total cholesterol. 
Table 2. Effect on Ezetimibe on PCSK9 in Clinical Trials

\begin{tabular}{|c|c|c|}
\hline Intervention & Treatment Duration & Change in Serum PCSK9 Level (\%) \\
\hline $\begin{array}{l}\text { Cross-sectional study } \\
\text { ( } \mathrm{n}=454) \text { in } 254 \text { healthy } \\
\text { controls ( } 117 \text { men, } \\
137 \text { women), } \\
59 \text { hypercholesterolemic } \\
\text { patients without drug } \\
\text { therapy, } 98 \text { patients } \\
\text { receiving statins } \\
(55 \text { atorvastatin, } \\
27 \text { rosuvastatin, } \\
14 \text { simvastatin, and } \\
2 \text { pravastatin), } 39 \text { patients } \\
\text { receiving statins + ezetimibe, } \\
\text { and } 4 \text { patients receiving } \\
\text { ezetimibe } 58,59\end{array}$ & $\geq 3 \mathrm{mo}$ & $\begin{array}{l}\text { Hyperlipidemic patients: }+11 \% \text { vs } \\
\text { controls }(\mathrm{p}<0.04) \\
\text { Statin monotherapy: }+45 \% \text { vs } \\
\text { controls }(\mathrm{p}<0.001) \\
\text { Statin }+ \text { ezetimibe: }+77 \% \text { vs controls }(\mathrm{p}<0.001) \\
\text { Statin }+ \text { ezetimibe: }+22 \% \text { vs statin } \\
\text { monotherapy ( }=0.001 \text { ) } \\
\text { Ezetimibe: no significant difference } \\
\text { vs controls ( } \mathrm{p}=\mathrm{NS})\end{array}$ \\
\hline $\begin{array}{l}\text { Ezetimibe } 10 \mathrm{mg} / \text { day vs simvastatin } \\
40 \mathrm{mg} / \text { day vs } \\
\text { ezetimibe }+ \text { simvastatin } \\
(72 \text { healthy men })^{43}\end{array}$ & 14 days & $\begin{array}{l}\text { Ezetimibe: }+0.09 \pm 12.4 \%(\mathrm{p}=0.80) \\
\text { Simvastatin: }+3.3 \pm 11.6 \%(\mathrm{p}=0.11) \\
\text { Ezetimibe }+ \text { simvastatin: }+5.5 \pm 9.5 \%(\mathrm{p}=0.0129)\end{array}$ \\
\hline
\end{tabular}

as a result of adverse events were found, with only one case of transaminase elevation greater than 3 times the upper limit of normal (ULN). Six phase II trials are currently evaluating AMG 145 for long-term reduction in LDL-C and safety (Table 3). Likewise, LGT209 (Novartis Pharmaceuticals Corp., East Hanover, NJ,) and PF04950615 (formerly RN316; Pfizer Inc., New York, NY) are both monoclonal antibodies in phase II trials (NCT01350141, NCT01243151, NCT01342211).

The investigational compound furthest along in the clinical trial process is REGN727, also known as SAR236552 (Regeneron Pharmaceuticals, Tarrytown, NY, and Sanofi-Aventis, Cambridge, MA), with several completed phase I and phase II trials. Phase I trials included both single-dose studies and a multidose study to assess efficacy and optimal dosing. ${ }^{68}$ The single-dose studies randomized 40 participants to intravenous therapy in a 3:1 manner, with 8 subjects in each group for doses of $0.3,1,3,6$, and $12 \mathrm{mg} / \mathrm{kg}$ and 32 others to receive subcutaneous therapy, again in a 3:1 manner, with 8 subjects in each group for doses of 50, 100, 150, and $250 \mathrm{mg}$. All participants were healthy volunteers between 18 and 65 years old with a body mass index of $18-30 \mathrm{~kg} / \mathrm{m}^{2}$ and LDL-C greater than $100 \mathrm{mg} / \mathrm{dl}$ who were not receiving any other lipid-lowering agents. In the multidose study, patients were randomized into three distinct arms: heterozygous familial hypercholesterolemia, LDL-C greater than $100 \mathrm{mg} / \mathrm{dl}$, and receiving atorvastatin $(\mathrm{n}=21$; 6 placebo; 15 REGN727); nonfamilial hypercho-

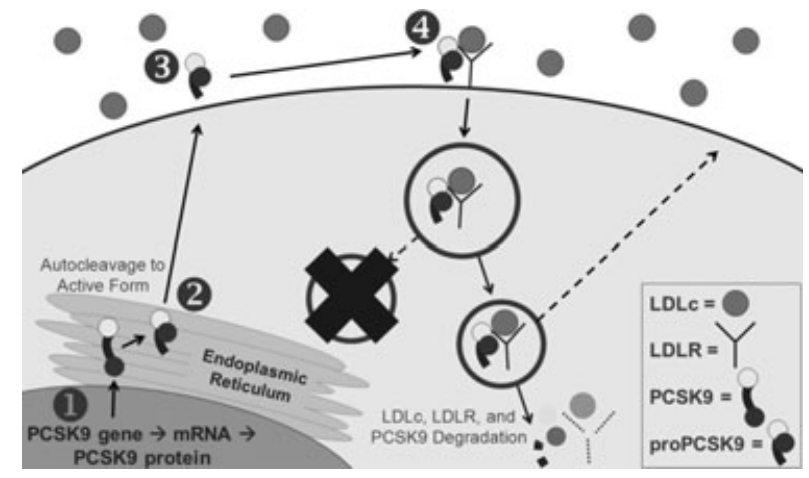

Figure 3. Four potential drug therapy targets within the low-density lipoprotein receptor (LDLR)-proprotein convertase subtilisin/kexin type 9 (PCSK9) pathway have been proposed: (1) reduction of the PCSK9 messenger RNA (e.g., small interfering RNA or antisense oligonucleotide-mediated gene silencing); (2) inhibition of autocleavage in the endoplasmic reticulum from proPCSK9 to the active form; (3) prevention of PCSK9 excretion from the cell or direct binding of PCSK9 in the circulation; and (4) inhibition of the LDLR-PCSK9 binding at the plasma membrane (e.g., monoclonal antibody to PCSK9). LDLc = low-density lipoprotein cholesterol.

lesterolemia, LDL-C greater than $100 \mathrm{mg} / \mathrm{dl}$, and receiving atorvastatin ( $\mathrm{n}=30 ; 6$ placebo; 24 REGN727); and nonfamilial hypercholesterolemia, LDL-C greater than $130 \mathrm{mg} / \mathrm{dl}$, and receiving a modified diet only $(\mathrm{n}=10 ; 2$ placebo; 8 REGN727). All participants were between 18 and 65 years old, had a body mass index of 18$35 \mathrm{~kg} / \mathrm{m}^{2}$, and had no known atherosclerotic vascular disease or diabetes mellitus. Participants within each arm were randomized to receive REGN727 50, 100, or 150 mg subcutaneously on weeks 0,4 , and 6 . The primary end point for all 
Table 3. Proprotein Convertase Subtilisin/Kexin Type 9-Inhibiting Agents in the Pipeline ${ }^{a}$

\begin{tabular}{|c|c|c|c|}
\hline Investigational Agent & Manufacturer & Stage of Development & $\begin{array}{l}\text { Ongoing Trials } \\
\text { (ClinicalTrials. }^{\text {gov identifier) }}{ }^{\mathrm{b}}\end{array}$ \\
\hline \multicolumn{4}{|l|}{ Antisense oligonucleotides } \\
\hline BMS-844421 & $\begin{array}{l}\text { Bristol-Myers Squibb and } \\
\text { Isis Pharmaceuticals }\end{array}$ & Phase I & $\begin{array}{l}\text { NCT01082562; terminated for } \\
\text { undisclosed reasons }\end{array}$ \\
\hline SPC-5001 & Santaris Pharma A/S & Phase I & $\begin{array}{l}\text { NCT01350960; terminated for } \\
\text { undisclosed reasons }\end{array}$ \\
\hline \multicolumn{4}{|l|}{ Small interfering RNA } \\
\hline ALN-PCSO2 & Alnylam Pharmaceuticals, Inc. & Phase I & $\begin{array}{l}\text { NCT01437059; anticipated } \\
\text { completion September } 2012\end{array}$ \\
\hline \multicolumn{4}{|l|}{ Monoclonal antibodies } \\
\hline AMG 145 & Amgen Inc. & Phase II and III & $\begin{array}{l}\text { NCT01375751 (phase II); } \\
\text { anticipated completion July } 2012 \\
\text { NCT01375764 (phase II); } \\
\text { anticipated completion July } 2012 \\
\text { NCT01375777 (phase II); } \\
\text { anticipated completion April } 2012 \\
\text { NCT01380730 (phase II); } \\
\text { anticipated completion May } 2012 \\
\text { NCT01439880 (phase II); } \\
\text { anticipated completion May } 2016 \\
\text { NCT01516879 (phase II); } \\
\text { anticipated completion April } 2014 \\
\text { NCT01624142 (phase III); } \\
\text { anticipated completion April } 2016\end{array}$ \\
\hline LGT209 & $\begin{array}{l}\text { Novartis Pharmaceuticals } \\
\text { Corporation }\end{array}$ & Phase II & Anticipated completion 2017 \\
\hline $\begin{array}{l}\text { PF-04950615 } \\
\text { (formerly RN316) }\end{array}$ & Pfizer Inc. & Phase II & $\begin{array}{l}\text { NCT01350141; anticipated } \\
\text { completion February } 2012 \\
\text { NCT01342211; anticipated } \\
\text { completion March } 2012\end{array}$ \\
\hline $\begin{array}{l}\text { REGN727 } \\
\text { (also known as SAR236552) }\end{array}$ & $\begin{array}{l}\text { Regeneron Pharmaceuticals } \\
\text { and Sanofi-Aventis }\end{array}$ & Phase III (recruiting) & $\begin{array}{l}\text { NCT01507831; anticipated } \\
\text { completion January } 2015\end{array}$ \\
\hline
\end{tabular}

${ }^{a}$ All investigational agents that have been tested in clinical trials, to date, are included.

${ }^{\mathrm{b}}$ Descriptions of each trial are available from the ClinicalTrials.gov Web site (http://clinicaltrials.gov).

phase I trials was the incidence and severity of treatment adverse effects. Secondary end points included relative and absolute change in LDL-C and total cholesterol, as well as serum lipid and lipoprotein levels.

REGN727 was found to be relatively safe in both the single-dose and multidose studies, with the most common adverse effects being headache and mild injection-site reactions. No subject discontinued the study early due to serious adverse events. No subject experienced liver toxicity as evidenced by no subjects with aspartate aminotransferase or alanine aminotransferase levels greater than 3 times ULN. Five out of the 39 subjects receiving REGN727 and also on atorvastatin (13\%) had an increase in their creatine kinase (CK) levels of greater than 3 times the ULN; however, no CK levels greater than 10 times the ULN were seen.

These phase I trials also shed light on important efficacy measures. In the single-dose trials, all doses in both the intravenous and subcutaneous groups resulted in a statistically significant reduction in LDL-C levels from baseline versus placebo $(\mathrm{p}<0.001)$. A dose-response relationship was seen in the lowering of LDL-C, with a maximum mean reduction of $65.4 \%$ in the intravenous group and $45.7 \%$ in the subcutaneous group. Likewise, the LDL-C lowering duration was also affected by dose, with the full effect of the intravenous $12 \mathrm{mg} / \mathrm{kg}$ dose maintained for 64 days compared with 22 days in the 250-mg subcutaneous group. Time to maximal benefit was seen in approximately 2 weeks. This is generally faster than the approximate 4 weeks previously observed with statins. In addition, patients with the four highest doses in the intravenous group and the three highest doses in the subcutaneous group reached a mean LDL-C or less than $70 \mathrm{mg} / \mathrm{dl}$.

Similar results were found in the multidose trial. At week 8, REGN727 significantly reduced 
LDL-C levels in all arms, and a dose-response relationship was seen. Interestingly, the effects of REGN727 appeared to be additive to atorvastatin and not synergistic. Similar mean percent reductions were seen in the patients receiving both subcutaneous REGN727 $150 \mathrm{mg}$ and atorvastatin compared with those not receiving atorvastatin $(-55.7 \%$ in the patients with familial hypercholesterolemia taking atorvasatin versus $-64.7 \%$ in the patients with nonfamilial hypercholesterolemia taking atorvastatin versus $-57.0 \%$ in the patients with nonfamilial hypercholesterolemia not taking atorvastatin). Finally, the duration of maximal effect was longer in patients not taking atorvastatin. This could support the theory that statins stimulate production of PCSK9, leading to an increased clearance of REGN727.

In a double-blind, placebo-controlled randomized phase II trial, 183 patients with LDL-C levels greater than $100 \mathrm{mg} / \mathrm{dl}$ who were receiving stable doses of atorvastatin (10-40 mg for $\geq$ 6 wks) were randomized to subcutaneous placebo every 2 weeks; REGN727 50, 100, or $150 \mathrm{mg}$ every 2 weeks; or REGN727 200 or $300 \mathrm{mg}$ every 4 weeks alternating with placebo every 2 weeks for a treatment duration of 12 weeks. ${ }^{69}$ The primary efficacy end point was change in LDL-C levels, with secondary end points consisting of safety outcomes and changes in other laboratory markers. Similar to the phase I trials, LDL-C level was reduced by $39.6-72.4 \%$ in all treatment arms versus $5.1 \%$ with placebo at week 12 ( $\mathrm{p}<0.001$ for all doses), and a doseresponse relationship existed. From 89\%-100\% of the REGN727 recipients versus 16\% of placebo recipients achieved a target LDL-C of less than $100 \mathrm{mg} / \mathrm{dl}$, whereas an LDL-C of less than $70 \mathrm{mg} / \mathrm{dl}$ was achieved by $46-100 \%$ of the REGN727 recipients versus 3\% of placebo recipients. Interestingly, the group receiving the dosage of subcutaneous REGN727 $150 \mathrm{mg}$ every 2 weeks achieved the lowest LDL-C level and was the only group to have $100 \%$ of recipients achieve an LDL-C level of less than $70 \mathrm{mg} / \mathrm{dl}$. Overall, the every-2-weeks dosing schedule appeared more advantageous than the every-4weeks regimens despite using higher doses in the every-4-weeks groups. Six patients prematurely discontinued REGN727 as a result of adverse events: one in the 100-mg every-2-weeks group (neutropenia), one in the 150-mg every-2weeks group (fatigue), three in the 200-mg every-4-weeks group (injection-site rash, chest pain, and combined headache and nausea), and one in the 300-mg every-4-weeks group (leuko- cytoclastic vasculitis). The leukocytoclastic vasculitis resolved after discontinuation of the medication and steroid therapy. No adverse effect-related discontinuations occurred in the placebo group; however, one patient did have CK levels greater than 10 times the ULN, whereas no patients experienced this adverse effect in the REGN727 groups. No elevations in aspartate aminotransferase or alanine aminotransferase levels were seen in this study.

The results of these trials are limited by the small number of participants, use of relatively healthy volunteers without major comorbidities, and short trial duration. The results of the actively recruiting phase III trial are highly anticipated, as this will help to answer some of the questions regarding long-term safety and efficacy with this investigational compound.

The use of the current PCSK9-inhibiting modalities may be limited by their intravenous and subcutaneous use. Oral administration is often the preferred route by patients because it is noninvasive and easy to self-administer. Multiple administrations of the medication will be necessary because the therapy is intended for long-term use. Safety and tolerability are other important concepts in the approval and use of a drug. Adverse effects in animal models have been minimal with the exception of one study in which mice with hepatocytes lacking PCSK9 had impaired liver regeneration after a partial hepatectomy. ${ }^{70}$ Caution must be used, however, in extrapolating results from animal models to humans. As previously noted, several humans with PCSK9 LOF mutations lacked neurologic or functional alterations. Likewise, adverse effects noted thus far in early phase I and II trials have been minimal. Long-term, large-scale trials will be needed to establish the long-term safety profile of PCSK9 inhibitors.

\section{Conclusion}

Optimal reduction in LDL-C continues to be a problem for certain cohorts of patients with hypercholesterolemia in whom statin therapy is not tolerated or LDL-C goals are not met despite maximal drug doses. PCSK9 inhibition represents a potential new approach for LDL-C lowering, as monotherapy or in addition to statins, with minimal adverse effects experienced to date. More research is needed as much is still unknown concerning PCSK9's mechanism of action, regulation, and factors affecting its function. Likewise, clinical trials evaluating the use 
of PCSK9 inhibition are still in their early stages, and more data are needed before the place in therapy of this new class of drugs is realized.

\section{Addendum}

Four phase II trials of AMG 145 have been published following their presentation at the American Heart Association 2012 Conference. The trials involve patients with familial hypercholesterolemia (RUTHERFORD, NCT01375751), statin-intolerant patients (GAUSS, NCT01375764), patients with elevated low-density lipoprotein cholesterol (LDL-C) but in whom treatment was not mandated by National Cholesterol Education Program Adult Treatment Panel III (NCEP ATPIII) criteria (MENDEL, NCT01375777) and hypercholesterolemic subjects not optimally managed on statin therapy with or without ezetimibe (LAPLACE-TIMI 57, NCT01380730). ${ }^{71-74}$

In GAUSS, statin intolerance was defined as "the inability to tolerate at least one statin at any dose OR an inability to increase statin dose above weekly maximums of rosuvastatin $35 \mathrm{mg}$ (5 mg/day); atorvastatin $70 \mathrm{mg}$ (10 mg/day); simvastatin $140 \mathrm{mg}$ (20 mg/day); pravastatin $140 \mathrm{mg}$ (20 mg/day); lovastatin $140 \mathrm{mg}(20 \mathrm{mg} /$ day); or fluvastatin $280 \mathrm{mg}$ (40 mg/day), because of intolerable myalgia (muscle pain, soreness, weakness, or cramps) or myopathy (myalgia plus elevated creatinine kinase) and having symptom improvement or resolution with statin discontinuation."71

Exclusion criteria for all trials included: heart failure defined as New York Heart Association Class III or IV or left ventricular ejection fraction (LVEF) less than 30\%; major cardiovascular, cerebrovascular, pulmonary, or venous event within 3 months of randomization; currently on anticoagulants, corticosteroids or cyclosporine within 3 months of randomization; uncontrolled cardiac arrhythmia or thyroid disease; stage 2 hypertension or worse; renal dysfunction defined as estimated glomerular filtration rate less than $30 \mathrm{ml} / \mathrm{min}$, liver disease defined as AST or ALT $>2 \times$ upper limit of normal (ULN) or creatinine kinase $>3 \times$ ULN; use of apheresis or lipid lowering medications not otherwise tested in the trials; triglycerides greater than $400 \mathrm{mg} /$ $\mathrm{dl}$; type I diabetes mellitus (T1DM) and newly diagnosed type II diabetes mellitus (T2DM) or with a hemoglobin Alc $>8.5 \%$. In addition, patients in the MENDEL trial were excluded if their 10-year Framingham risk score for coronary heart disease was greater than $10 \%$.
Results for all four trials can be found in Table 1. For all AMG 145 doses, maximum LDL-C reduction was seen at 2 weeks and maintained throughout the rest of the trial regardless of dosing every 2 or 4 weeks. Importantly, maximal LDL-C reduction with statin use is $62 \%$ using rosuvastatin $40 \mathrm{mg}$ daily. LDL-C reductions of up to $66.1 \%$ were seen in high-risk patients already on statin therapy but not at goal (LAPLACE TIMI-57) and up to 63\% in patients unable to tolerate statin therapy (GAUSS). Likewise, a clinically significant goal for reduced cardiovascular events in patients at high risk for cardiovascular disease in practice is a goal LDL-C of less than $70 \mathrm{mg} / \mathrm{dl}$. Up to $93 \%$ of patients not at goal at baseline but already on a statin were able to meet this goal with the use of AMG 145 at 12 weeks compared to only $1.3 \%$ of patients on placebo, essentially statin therapy alone. ${ }^{72}$ Similarly, up to $65 \%$ of familial hypercholesterolemia (FH) patients, a population historically known to be difficult to manage with statin therapy alone or in combination with other lipid-lowering medications, achieve a LDL-C of less than $70 \mathrm{mg} / \mathrm{dl}$ using AMG 145 compared to zero patients on placebo. ${ }^{74}$ AMG 145 may prove to be an option for patients unable to tolerate statins by providing adequate LDL-C reduction to achieve LDL-C goals without having the myalgias and myopathies often limiting the use of statin therapy.

Most commonly noted adverse effects seen in all four trials were nasopharyngitis, headache, injection-site reactions, cough, and nausea. No patients stopped treatment due to treatmentrelated serious adverse events in any of the trials. No relationship was found between the number or severity of ADRs and dosing or dose frequency.

A few limitations of these trials are their relatively short duration and small sample sizes for each group. Also, these trials lack any hard outcomes related to prevention of cardiovascular events. These outcomes hope to be better delineated and evaluated in the upcoming phase III trials. The exclusion criteria were generally broad for all the trials as well. Several patient populations were excluded that may commonly be seen in practice in high risk cardiovascular patients. The results of these trials and the use of AMG 145 may not be applicable or extrapolated to these populations. In GAUSS and MENDEL, the use of ezetimibe was unblinded and may contribute to an imbalance in ADR reporting. Finally in GAUSS, the definition for "statin 
intolerance" is subjective; however, a standard definition is lacking and no current guidance exists for appropriate treatment of these patients.

REGN727/SAR236553 (REGN727) also had another phase II trial published at the end of 2012. This multicenter, double-blind, placebocontrolled trial included 92 patients with a LDL-C $\geq 100 \mathrm{mg} / \mathrm{dl}$ after treatment with $10 \mathrm{mg}$ of atorvastatin daily for at least 7 weeks. ${ }^{75}$ These patients were randomized to 8 weeks of treatment with one of three regimens: high-dose atorvastatin (80 mg daily) plus REGN727 $150 \mathrm{mg}$ subcutaneously (SQ) once every 2 weeks $(\mathrm{n}=30)$, low-dose atorvastatin (10 mg daily) plus REGN727 $150 \mathrm{mg}$ SQ once every 2 weeks $(n=31)$, or high-dose atorvastatin plus placebo SQ once every 2 weeks $(n=31)$. Patients were then followed for an additional 8 weeks after treatment completion. Patients were excluded if they had T1DM, T2DM treated with insulin or poorly controlled (HgAlc $\geq 8.5 \%$ ), baseline AST/ALT $>2 \times$ ULN, triglycerides $>350 \mathrm{mg} / \mathrm{dl}$, any cardiovascular or cerebrovascular event or procedure within 6 months before the screening visit, uncontrolled thyroid disease within 12 weeks prior to randomization, or were on other antihyperlipidemic medications. Note these criteria are similar to exclusion criteria used in the AMG 145 phase I and II trials to date.

Baseline characteristics of all patients included mean age of 56.9 years (25\% were greater than 65 yrs old), $40 \%$ male, $87 \%$ white, average body mass index 29.5, 15\% with controlled T2DM, $51 \%$ with hypertension, $5 \%$ with cerebrovascular disease, $4 \%$ with CAD or PVD, mean LDL-C of $122.6 \mathrm{mg} / \mathrm{dl}$, and mean total cholesterol of $203.4 \mathrm{mg} / \mathrm{dl}$.

Eighty patients $(87 \%)$ completed the 8 week treatment period. Of the 92 patients randomized, four did not have LDL-C levels available after the baseline values and therefore were not included in the modified intention to treat analysis. Percent reduction from baseline LDL-C at 8weeks (least-squares mean $[ \pm S]$ ) was $73.2 \pm 3.5 \%$ in the atorvastation $80 \mathrm{mg}$ plus REGN727 group compared to $17.3 \pm 3.5 \%$ in the placebo group $(p<0.001)$ and $66.2 \pm 3.5 \%$ in the atorvastatin $10 \mathrm{mg}$ plus REGN727 group $(p=0.16)$. Similar to AMG 145, low LDL-C was achieved by week 2 following the first dose of REGN727 and was maintained throughout the remainder of treatment. Interestingly, no difference was seen when comparing the two doses of statins in addition to REGN727; therefore, goal LDL-C may be achievable in patients while utilizing lower statin doses. This could decrease the side effects and intolerances seen with statin therapy. The additional $25 \%$ reduction seen at 2 weeks after patients changed to atorvastatin $80 \mathrm{mg}$ plus placebo from atorvastatin $10 \mathrm{mg}$ during the run-in phase would be predicted by the rule of 7 (approximate 7\% additional decrease in LDL-C for each doubling of statin dose). All patients who received REGN727 (100\%) attained a LDL-C less than $100 \mathrm{mg} / \mathrm{dl}$ versus only $52 \%$ of patients on placebo. Similarly, 90\% of all patients who received REGN727 achieved a LDL-C less than $70 \mathrm{mg} / \mathrm{dl}$ compared to only $17 \%$ of those on placebo. Other changes in lipid parameters seen were a modest increase in HDL in the REGN727 plus atorvastatin $80 \mathrm{mg}$ compared with statin therapy alone $(p=0.005)$ and a decrease in both triglyceride and LPa levels ( $\mathrm{p}<0.001$ for both).

Similar adverse drug reaction percentages were experienced across the groups: $61 \%$ of patients in the placebo arm, $45 \%$ in the REGN727 plus atorvastatin $10 \mathrm{mg}$ group, and $60 \%$ in the REGN727 plus atorvastatin $80 \mathrm{mg}$ group ( $p=$ non-significant). Permanent discontinuation of treatment due to adverse events occurred in four patients in the placebo arm, one patient in the REGN727 plus atorvastatin $80 \mathrm{mg}$ arm. One patient with an AST value $>3 \times$ ULN and one patient with a bilirubin $>3 \times$ ULN were in the REGN727 plus atorvastatin $80 \mathrm{mg}$ group. However, the placebo group had a patient with a CK level $>3 \times$ ULN. Five patients prematurely discontinued study treatment owing to an adverse event that occurred during treatment, four in placebo group and one in the REGN727 plus atorvastatin $80 \mathrm{mg}$ group. More gastrointestinal side effects and musculoskeletal disorders were seen in the placebo group compared to the REGN727 groups; however, more dizziness and headaches were found in the REGN727 plus atorvastatin $80 \mathrm{mg}$ group than the placebo group. In general, REGN727 was well tolerated during the 8 weeks of therapy and is comparable to prior trials.

Overall, adding REGN727 to either 10 or $80 \mathrm{mg}$ of atorvastatin resulted in a significantly greater reduction in LDL-C compared to atorvastatin alone in patients with primary hypercholesterolemia. A few limitations of the study were its small sample size and short duration. Also, the patient population included was lowrisk for cardiovascular disease; therefore, results 
of the study many not be applicable to all hypercholesterolemia patients.

Finally, more data has come available in terms of the effect of ezetimibe on PCSK9 levels (Table 2). In GAUSS, the absolute value of free PCSK9 at baseline in the ezetimibe group was 389.9 $\mathrm{ng} / \mathrm{ml}$ with a mean value at 12 weeks of 376.2 $\mathrm{ng} / \mathrm{ml}$ (95\% confidence interval, CI 343.6 $408.9 \mathrm{ng} / \mathrm{dl}){ }^{71}$ This is an absolute reduction from baseline by $15.6 \mathrm{ng} / \mathrm{ml}$ (CI - $46.4-15.2$ ) and $1.5 \%$ (CI $-10.1-7.2 \%)$ reduction from baseline. These results suggest a negligible effect of ezetimibe on PCSK9 levels and this is comparable to prior data in humans.

\section{References}

1. Brugts JJ, Yetgin T, Hoeks SE, et al. The benefits of statins in people without established cardiovascular disease but with cardiovascular risk factors: meta-analysis of randomised controlled trials. BMJ 2009;338:b2376.

2. Centers for Disease Control (CDC). Vital signs: prevalence, treatment, and control of high levels of low-density lipoprotein cholesterol-united states, 1999-2002 and 2005-200. MMWR Morb Mortal Wkly Rep 2011;60(4):109-14.

3. Zhang DW, Lagace TA, Garuti R, et al. Binding of proprotein convertase subtilisin/kexin type 9 to epidermal growth factorlike repeat A of low density lipoprotein receptor decreases receptor recycling and increases degradation. J Biol Chem 2007;282(25):18602-12.

4. Duff CJ and Hooper NM. PCSK9: an emerging target for treatment of hypercholesterolemia. Expert Opin Ther Targets 2011;15(2):157-68.

5. Farnier M. The role of proprotein convertase subtilisin/kexin type 9 in hyperlipidemia: focus on therapeutic implications. Am J Cardiovasc Drugs 2011;11(3):145-52.

6. Horton JD, Cohen JC, Hobbs HH. PCSK9: a convertase that coordinates LDL catabolism. J Lipid Res 2009;50(Suppl):S172-7.

7. Grefhorst A, McNutt MC, Lagace TA, Horton JD. Plasma PCSK9 preferentially reduces liver LDL receptors in mice. J Lipid Res 2008;49(6):1303-11.

8. Langhi C, Le May C, Gmyr V, et al. PCSK9 is expressed in pancreatic delta-cells and does not alter insulin secretion. Biochem Biophys Res Commun 2009;390(4):1288-93.

9. Leblond F, Seidah NG, Precourt LP, Delvin E, Dominguez M, Levy E. Regulation of the proprotein convertase subtilisin/kexin type 9 in intestinal epithelial cells. Am J Physiol Gastrointest Liver Physiol 2009;296(4):G805-15.

10. Schmidt RJ, Beyer TP, Bensch WR, et al. Secreted proprotein convertase subtilisin/kexin type 9 reduces both hepatic and extrahepatic low-density lipoprotein receptors in vivo. Biochem Biophys Res Commun 2008;370(4):634-40.

11. Seidah NG, Benjannet S, Wickham L, et al. The secretory proprotein convertase neural apoptosis-regulated convertase 1 (NARC-1): liver regeneration and neuronal differentiation. Proc Natl Acad Sci USA 2003;100(3):928-33.

12. Jeong HJ, Lee HS, Kim KS, Kim YK, Yoon D, Park SW. Sterol-dependent regulation of proprotein convertase subtilisin/ kexin type 9 expression by sterol-regulatory element binding protein-2. J Lipid Res 2008;49(2):399-409.

13. Costet P, Cariou B, Lambert G, et al. Hepatic PCSK9 expression is regulated by nutritional status via insulin and sterol regulatory element-binding protein 1c. J Biol Chem 2006;281 (10):6211-8

14. Maxwell KN, Soccio RE, Duncan EM, Sehayek E, Breslow JL. Novel putative SREBP and LXR target genes identified by microarray analysis in liver of cholesterol-fed mice. J Lipid Res 2003;44(11):2109-19.
15. Browning JD, Horton JD. Fasting reduces plasma proprotein convertase, subtilisin/kexin type 9 and cholesterol biosynthesis in humans. J Lipid Res 2010;51(11):3359-63.

16. Persson L, Cao G, Stahle L, et al. Circulating proprotein convertase subtilisin kexin type 9 has a diurnal rhythm synchronous with cholesterol synthesis and is reduced by fasting in humans. Arterioscler Thromb Vasc Biol 2010;30(12):266672.

17. Radhakrishnan A, Goldstein JL, McDonald JG, Brown MS. Switch-like control of SREBP-2 transport triggered by small changes in ER cholesterol: a delicate balance. Cell Metab 2008;8(6):512-21.

18. Denis M, Marcinkiewicz J, Zaid A, et al. Gene inactivation of proprotein convertase subtilisin/kexin type 9 reduces atherosclerosis in mice. Circulation 2012;125(7):894-901.

19. Shan L, Pang L, Zhang R, Murgolo NJ, Lan H, Hedrick JA. PCSK9 binds to multiple receptors and can be functionally inhibited by an EGF-A peptide. Biochem Biophys Res Commun 2008;375(1):69-73.

20. Takahashi S, Sakai J, Fujino T, et al. The very low-density lipoprotein (VLDL) receptor: characterization and functions as a peripheral lipoprotein receptor. J Atheroscler Thromb 2004;11(4):200-8.

21. Tacken PJ, Hofker MH, Havekes LM, van Dijk KW. Living up to a name: the role of the VLDL receptor in lipid metabolism. Curr Opin Lipidol 2001;12(3):275-9.

22. Roubtsova A, Munkonda MN, Awan Z, et al. Circulating proprotein convertase subtilisin/kexin 9 (PCSK9) regulates VLDLR protein and triglyceride accumulation in visceral adipose tissue. Arterioscler Thromb Vasc Biol 2011;31(4):785-91.

23. Baass A, Dubuc G, Tremblay M, et al. Plasma PCSK9 is associated with age, sex, and multiple metabolic markers in a population-based sample of children and adolescents. Clin Chem 2009;55(9):1637-45.

24. Lakoski SG, Lagace TA, Cohen JC, Horton JD, Hobbs HH. Genetic and metabolic determinants of plasma PCSK9 levels. J Clin Endocrinol Metab 2009;94(7):2537-43.

25. Abifadel M, Varret M, Rabes JP, et al. Mutations in PCSK9 cause autosomal dominant hypercholesterolemia. Nat Genet 2003;34(2):154-6.

26. Horton JD, Cohen JC, Hobbs HH. Molecular biology of PCSK9: its role in LDL metabolism. Trends Biochem Sci 2007;32(2):71-7.

27. Naoumova RP, Tosi I, Patel D, et al. Severe hypercholesterolemia in four British families with the D374Y mutation in the PCSK9 gene: long-term follow-up and treatment response. Arterioscler Thromb Vasc Biol 2005;25(12):2654-60.

28. Humphries SE, Whittall RA, Hubbart CS, et al. Simon Broome Familial Hyperlipidaemia Register Group and Scientific Steering Committee. Genetic causes of familial hypercholesterolaemia in patients in the UK: relation to plasma lipid levels and coronary heart disease risk. J Med Genet 2006;43(12): 943-9.

29. Cunningham D, Danley DE, Geoghegan KF, et al. Structural and biophysical studies of PCSK9 and its mutants linked to familial hypercholesterolemia. Nat Struct Mol Biol 2007;14 (5):413-9.

30. Fisher TS, Lo Surdo P, Pandit S, et al. Effects of $\mathrm{pH}$ and low density lipoprotein (LDL) on PCSK9-dependent LDL receptor regulation. J Biol Chem 2007;282(28):20502-12.

31. Cohen JC, Boerwinkle E, Mosley TH Jr, Hobbs HH. Sequence variations in PCSK9, low LDL, and protection against coronary heart disease. N Engl J Med 2006;354(12):1264-72.

32. Kotowski IK, Pertsemlidis A, Luke A, et al. A spectrum of PCSK9 alleles contributes to plasma levels of low-density lipoprotein cholesterol. Am J Hum Genet 2006;78(3):410-22.

33. Hallman DM, Srinivasan SR, Chen W, Boerwinkle E, Berenson GS. Relation of PCSK9 mutations to serum low-density lipoprotein cholesterol in childhood and adulthood (from the Bogalusa Heart Study). Am J Cardiol 2007;100(1):69-72.

34. Benn M, Nordestgaard BG, Grande P, Schnohr P, TybjaergHansen A. PCSK9 R46L, low-density lipoprotein cholesterol levels, and risk of ischemic heart disease: 3 independent stud- 
ies and meta-analyses. J Am Coll Cardiol 2010;55(25):283342.

35. Chasman DI, Giulianini F, Macfadyen J, Barratt BJ, Nyberg F, Ridker PM. Genetic determinants of statin-induced lowdensity lipoprotein cholesterol reduction: the Justification for the Use of statins in Prevention: an Intervention Trial Evaluating Rosuvastatin (JUPITER) trial. Circ Cardiovasc Genet 2012;5(2):257-64.

36. Cholesterol Treatment Trialists' (CTT) Collaboration, Baigent C, Blackwell L, Emberson J, Holland LE, Reith C, Bhala N, et al. Efficacy and safety of more intensive lowering of LDL cholesterol: a meta-analysis of data from 170,000 participants in 26 randomised trials. Lancet 2010;376(9753):1670-81.

37. Abifadel M, Rabes JP, Devillers M, et al. Mutations and polymorphisms in the proprotein convertase subtilisin kexin 9 (PCSK9) gene in cholesterol metabolism and disease. Hum Mutat 2009;30(4):520-9.

38. Zhao Z, Tuakli-Wosornu Y, Lagace TA, et al. Molecular characterization of loss-of-function mutations in PCSK9 and identification of a compound heterozygote. Am J Hum Genet 2006;79(3):514-23.

39. Hooper AJ, Marais AD, Tanyanyiwa DM, Burnett JR. The C679X mutation in PCSK9 is present and lowers blood cholesterol in a southern African population. Atherosclerosis 2007;193(2):445-8.

40. Cariou B, Ouguerram K, Zair Y, et al. PCSK9 dominant negative mutant results in increased LDL catabolic rate and familial hypobetalipoproteinemia. Arterioscler Thromb Vasc Biol 2009;29(12):2191-7.

41. Fasano T, Cefalu AB, Di Leo E, et al. A novel loss of function mutation of PCSK9 gene in white subjects with low-plasma low-density lipoprotein cholesterol. Arterioscler Thromb Vasc Biol 2007;27(3):677-81

42. Ai D, Chen C, Han S, et al. Regulation of hepatic LDL receptors by mTORCl and PCSK9 in mice. J Clin Invest 2012;122 (4): $1262-70$

43. Gouni-Berthold I, Berthold HK, Gylling H, et al. Effects of ezetimibe and/or simvastatin on LDL receptor protein expression and on LDL receptor and HMG-CoA reductase gene expression: a randomized trial in healthy men. Atherosclerosis 2008;198(1):198-207.

44. Mayne J, Dewpura T, Raymond A, et al. Plasma PCSK9 levels are significantly modified by statins and fibrates in humans. Lipids Health Dis 2008; $7: 22$.

45. Costet P, Hoffmann MM, Cariou B, Guyomarc'h Delasalle B, Konrad T, Winkler K. Plasma PCSK9 is increased by fenofibrate and atorvastatin in a non-additive fashion in diabetic patients. Atherosclerosis 2010;212(1):246-51.

46. Careskey HE, Davis RA, Alborn WE, Troutt JS, Cao G, Konrad RJ. Atorvastatin increases human serum levels of proprotein convertase subtilisin/kexin type 9. J Lipid Res 2008;49 (2):394-8.

47. Awan Z, Seidah NG, Macfadyen JG, et al. Rosuvastatin, proprotein convertase subtilisin/kexin type 9 (PCSK9) concentrations, and LDL cholesterol response: the JUPITER trial. Clin Chem 2012;58:183-9.

48. Welder G, Zineh I, Pacanowski MA, Troutt JS, Cao G, Konrad RJ. High-dose atorvastatin causes a rapid sustained increase in human serum PCSK9 and disrupts its correlation with LDL cholesterol. J Lipid Res 2010;51(9):2714-21.

49. Mayne J, Raymond A, Chaplin A, et al. Plasma PCSK9 levels correlate with cholesterol in men but not in women. Biochem Biophys Res Commun 2007;361(2):451-6.

50. Roberts WC. The rule of 5 and the rule of 7 in lipid-lowering by statin drugs. Am J Cardiol 1997;80(1):106-7.

51. Dubuc G, Chamberland A, Wassef $\mathrm{H}$, et al. Statins upregulate PCSK9, the gene encoding the proprotein convertase neural apoptosis-regulated convertase-1 implicated in familial hypercholesterolemia. Arterioscler Thromb Vasc Biol 2004;24 (8):1454-9.

52. Rashid S, Curtis DE, Garuti R, et al. Decreased plasma cholesterol and hypersensitivity to statins in mice lacking Pcsk9. Proc Natl Acad Sci USA 2005;102(15):5374-9.
53. Costet P. Molecular pathways and agents for lowering LDLcholesterol in addition to statins. Pharmacol Ther 2010;126 (3):263-78.

54. Troutt JS, Alborn WE, Cao G, Konrad RJ. Fenofibrate treatment increases human serum proprotein convertase subtilisin kexin type 9 levels. J Lipid Res 2010;51(2):345-51.

55. Noguchi T, Kobayashi J, Yagi K, et al. Comparison of effects of bezafibrate and fenofibrate on circulating proprotein convertase subtilisin/kexin type 9 and adipocytokine levels in dyslipidemic subjects with impaired glucose tolerance or type 2 diabetes mellitus: results from a crossover study. Atherosclerosis $2011 ; 217(1): 165-70$.

56. Lambert G, Ancellin N, Charlton F, et al. Plasma PCSK9 concentrations correlate with LDL and total cholesterol in diabetic patients and are decreased by fenofibrate treatment. Clin Chem 2008;54(6):1038-45.

57. Chan DC, Hamilton SJ, Rye KA, et al. Fenofibrate concomitantly decreases serum proprotein convertase subtilisin/kexin type 9 and very-low-density lipoprotein particle concentrations in statin-treated type 2 diabetic patients. Diabetes Obes Metab 2010;12(9):752-6.

58. Dubuc G, Tremblay M, Pare G, et al. A new method for measurement of total plasma PCSK9: clinical applications. J Lipid Res 2010;51(1):140-9.

59. Davignon J, Dubuc G. Statins and ezetimibe modulate plasma proprotein convertase subtilisin kexin-9 (PCSK9) levels. Trans Am Clin Climatol Assoc 2009;120:163-73.

60. Kastelein JJ, Akdim F, Stroes ES, et al. Simvastatin with or without ezetimibe in familial hypercholesterolemia. N Engl J Med 2008;358(14):1431-43.

61. Taylor AJ, Villines TC, Stanek EJ, et al. Extended-release niacin or ezetimibe and carotid intima-media thickness. N Engl J Med 2009;361(22):2113-22.

62. Rossebo AB, Pedersen TR, Boman $\mathrm{K}$, et al. Intensive lipid lowering with simvastatin and ezetimibe in aortic stenosis. N Engl J Med 2008;359(13):1343-56.

63. Mayne J, Dewpura T, Raymond A, et al. Novel loss-of-function PCSK9 variant is associated with low plasma LDL cholesterol in a French-Canadian family and with impaired processing and secretion in cell culture. Clin Chem 2011;57 (10): 1415-23

64. Liang H, Chaparro-Riggers J, Strop P, et al. PCSK9 antagonism reduces LDL-cholesterol in statin-treated hypercholesterolemic non-human primates. J Pharmacol Exp Ther 2012;340:228-36.

65. Ni YG, Di Marco S, Condra JH, et al. A PCSK9-binding antibody that structurally mimics the EGF(A) domain of LDLreceptor reduces LDL cholesterol in vivo. J Lipid Res 2011;52 (1):78-86.

66. Dias CSA, Smith B, Emery M, et al. A phase 1, randomized, double-blind, placebo-controlled, ascending single dose study to evaluate the safety, tolerability and pharmacodynamics of AMG145. Circulation (Suppl) 2011;124:A10701.

67. Dias C, Shaywitz A, Cooke B, Uy S, Emery M. Effects of AMG145, a fully human monoclonal antibody against PCSK9, on low-density lipoprotein cholesterol in subjects taking statins: a phase 1, randomized, double-blind, placebocontrolled, ascending study. J Am Coll Cardiol (Suppl) 2012;59:E1379.

68. Stein EA, Mellis S, Yancopoulos GD, et al. Effect of a monoclonal antibody to PCSK9 on LDL cholesterol. N Engl J Med 2012;366(12):1108-18.

69. McKenney JM, Koren MJ, Kereiakes DJ, Hanotin C, Ferrand AC, Stein EA. Safety and efficacy of a monoclonal antibody to proprotein convertase subtilisin/kexin type 9 serine protease, SAR236553/REGN727, in patients with primary hypercholesterolemia receiving ongoing stable atorvastatin therapy. J Am Coll Cardiol 2012;59:2344-53.

70. Zaid A, Roubtsova A, Essalmani R, et al. Proprotein convertase subtilisin/kexin type 9 (PCSK9): hepatocyte-specific low-density lipoprotein receptor degradation and critical role in mouse liver regeneration. Hepatology 2008;48(2): 646-54. 
71. Sullivan D, Olsson A, Scott R, et al. Effect of a monoclonal antibody to PCSK9 on low-density lipoprotein cholesterol levels in statin-intolerant patients: the GAUSS randomized trial. JAMA 2012;308(23):2497-506.

72. Giugliano R, Desai N, Kohli P, et al. Efficacy, safety, and tolerability of a monoclonal antibody to proprotein convertase subtilisin/kexin type 9 in combination with a statin in patients with hypercholesterolaemia (LAPLACE-TIMI 57): a randomized, placebo-controlled, dose-ranging, phase 2 study. Lancet 2012;9858:2007-17.

73. Koren M, Scott R, Kim J, et al. Efficacy, safety, and tolerability of a monoclonal antibody to proprotein convertase subtilisin/kexin type 9 as monotherpay in patients with hypercholesterolaemia (MENDEL): a randomized, doubleblind, placebo-controlled, phase 2 study. Lancet 2012;380 (9858): 1995-2006.

74. Raal F, Scott R, Somaratne R, et al. Low-density lipoprotein cholesterol-lowering effects of AMG 145, a monoclonal antibody to proprotein convertase subilisin/kexin type 9 serine protease in patients with heterozygous familial hypercholesterolemia: the reduction of LDL-C with PCSK9 inhibition in heterozygous familial hypercholesterolemia disorder (RUTHERFORD) randomized trial. Circulation 2012;126:2408-17.

75. Roth E, McKenney J, Hanotin C, Asset G, Stein E. Atorvastatin with or without an antibody to PCSK9 in primary hypercholesterolemia. N Engl J Med 2012;367:1891-900. 